\title{
Assessment of the association between increasing membrane pore size and endotoxin permeability using a novel experimental dialysis simulation set-up
}

Eva Schepers ${ }^{1 *}\left(\mathbb{D}\right.$, Griet Glorieux', Sunny Eloot ${ }^{1}$, Michael Hulko², Adriana Boschetti-de-Fierro², Werner Beck², Bernd Krause ${ }^{2}$ and Wim Van Biesen ${ }^{1}$

\begin{abstract}
Background: Membranes with increasing pore size are introduced to enhance removal of large uremic toxins with regular hemodialysis. These membranes might theoretically have higher permeability for bacterial degradation products. In this paper, permeability for bacterial degradation products of membranes of comparable composition with different pore size was investigated with a new in vitro set-up that represents clinical flow and pressure conditions.

Methods: Dialysis was simulated with an AK200 machine using a low-flux, high-flux, medium cut-off (MCO) or high cut-off (HCO) device ( $n=6 /$ type). A polyvinylpyrrolidone-solution (PVP) was recirculated at blood side. At dialysate side, a challenge solution containing a filtrated lysate of two water-borne bacteria (Pseudomonas aeruginosa and Pelomononas saccharophila) was infused in the dialysate flow (endotoxin $\geq 4 \mathrm{EU} / \mathrm{ml}$ ). Blood and dialysate flow were set at 400 and $500 \mathrm{ml} / \mathrm{min}$ for $60 \mathrm{~min}$. PVP was sampled before ( $\left(\mathrm{PV}_{\text {pre }}\right)$ and after ( $\left(\mathrm{PVP}_{\text {post }}\right)$ the experiment and dialysate after 5 and 55 min. Limulus Amebocyte Lysate (LAL) test was performed. Additionally, samples were incubated with a THP-1 cell line (24 h) and IL-1 $\beta$ levels were measured evaluating biological activity.

Results: The LAL-assay confirmed presence of $9.5 \pm 7.4 \mathrm{EU} / \mathrm{ml}$ at dialysate side. For none of the devices the LAL activity in PVP pre Vs. PVP post was significantly different. Although more blood side PVP solutions had a detectable amount of endotoxin using a highly sensitive LAL assay in the more open vs traditional membranes, the permeability for endotoxins of the 4 tested dialysis membranes was not significantly different but the number of repeats is small. None of the PVP solutions induced IL-1 $\beta$ in the THP-1 assay.

Conclusions: A realisitic in vitro dialysis was developed to assess membrane translocation of bacterial products. LAL activity on the blood side after endotoxin exposure did not change for all membranes. Also, none of the PVP post solutions induced IL-1 $\beta$ in the THP-1 bio-assay.
\end{abstract}

Keywords: Hemodialysis, Endotoxin, Water quality, Membrane permeability

\footnotetext{
* Correspondence: Eva.Schepers@UGent.be

'Department of Internal Medicine, Nephrology Division, Ghent University

Hospital, Gent, Belgium

Full list of author information is available at the end of the article
} 


\section{Background}

Novel insights in uremic toxicity over the last decade have revealed that retention products in the middle molecular weight range $15-45 \mathrm{kDa}$ might substantially contribute to the enhanced inflammation and cardiovascular mortality observed in patients with end stage kidney disease (ESKD) [1, 2]. Conventional high-flux dialyzers do not efficiently remove molecules in this molecular weight range, such as $\beta 2$-microglobulin $(\beta 2 \mathrm{M})$, tumor necrosis factor (TNF)- $\alpha$, interleukins (ILs), and complement factor D, resulting in their accumulation in patients with ESKD [3]. The theoretical advantages of high-flux over low-flux membranes are not completely translated in clinical advantages, as demonstrated in the HEMO and MPO study [4-7]. Hemodiafiltration with postdilution does result in enhanced removal of these middle molecules [8], but also here, evidence to support their advantages in the clinical setting is conflictive [9-11], and part of the reported doseresponse effect, with the largest effect observed in the subgroups with the highest substitution rates, might be due to confounding as patients in these subgroups typically have the best vascular access. In addition, hemo(dia)filtration increases technical complexity and cost of dialysis, and requires the application of high volumes of ultrapure dialysate and sterile substitution fluid with dedicated equipment.

Nowadays, there is a trend to further increase pore size and permeability of dialysis membranes to enhance removal of uremic toxins in the larger molecular weight range even when used in hemodialysis mode. The high cut-off (HCO) dialyzers allow elimination of molecules up to $45 \mathrm{kDa}$ [12] and remove specific middle molecules more effectively than standard high flux membranes $[13,14]$. The use of these membranes decreases inflammation and in vitro calcification, but also results in albumin loss $[15,16]$. More recently, membranes with a steeper cut-off at a lower molecular weight level than the HCO membranes, the so-called medium cutoff (MCO) membranes, have been introduced [17]. These membranes can even remove large toxins such as kappa and lambda free light chains [18], two compounds associated with inflammatory markers and mortality in CKD [19-22]. In a recent randomized cross-over trial, use of MCO dialyzers during a 12 week study period was associated with a more expressed reduction of inflammation than the use of conventional high-flux dialyzers. However, in this study, ultrapure dialysate was used [23].

The question arises whether these membranes with increasing pore size also have higher permeability for endotoxins and other bacterial degradation products potentially present in dialysis fluids. This permeability issue is relevant since chronic exposure of hemodialysis
(HD) patients to low levels of cytokine-inducing microbial components can potentially contribute to the microinflammatory status of these patients, thus neutralizing an eventual positive effect induced by their capacity of enhanced removal of pro-inflammatory uremic toxins $[24,25]$. Therefore, the request for ultrapure dialysate might become a more important concern as membrane pore size becomes larger, even when applied in hemodialysis mode. The International Organization for Standardization (ISO) published the ISO11663:2014 which states that the dialysate should contain less than 100 colony forming units (CFU)/ml for bacteria and less than 0.5 endotoxin units $(\mathrm{EU}) / \mathrm{ml}$ for endotoxin [26]. Standard methods to determine biological contamination of the dialysate are bacterial culture and the Limulus Amebocyte Lysate (LAL) assay. To test true biological response with more clinical relevance, bioassays, such as the one using the THP-1 cell line, can be applied [27].

Assessment of endotoxin transfer over membranes has until now only been performed in closed in vitro dialysis circuits. [28-32]. In vitro investigations using miniaturized dialyzer modules of membranes with increasing pore size have indicated that endotoxin permeability with lipopolysaccharide (LPS) isolated from E.coli O55:B5 as a challenge and the LAL assay as read-out does not increase with increasing pore size [33]. However, none of these models used clinically relevant blood and/or dialysate flows, contamination exposure was rather high in most studies, and the biological response was assessed in biological assays using whole blood or isolated peripheral blood mononuclear cells which coincides with a need for healthy donors, large variability and lower sensitivity compared to the THP-1 assay.

In the present study a more advanced and realistic dialysis set-up using full sized dialysers was developed that simulates the clinical situation in terms of flow rates and viscosity of the medium perfused in the blood compartment, and using full sized dialyzers. This set-up was used to assess commercial dialyzers of comparable composition but with different pore size for their permeability for bacterial degradation products by means of a biological assay sensitive to several bacterial components as read-out in addition to the LAL assay.

\section{Methods}

\section{Dialysis membranes}

The dialysis membranes to be evaluated for their endotoxin permeability were provided by the manufacturer (Polyflux ${ }^{\circ}$ 17 L, Revaclear 400, Theranova 400 and Theralite ${ }^{\mathrm{TM}}$ 2100, Baxter, Hechingen, Germany) and were composed of comparable polymers, but with a different pore size. Their main characteristics are summarized in Table 1. 
Table 1 Characteristics of dialyzers

\begin{tabular}{|c|c|c|c|c|c|c|}
\hline & Type & Sterilisation & Membrane Polymer & Effective Surface area $\left(\mathrm{m}^{2}\right)$ & UF-coefficient $(\mathrm{mL} / \mathrm{H} / \mathrm{mmHg})$ & Pore radius $^{\mathrm{a}}(\mathrm{nm})$ \\
\hline Polyflux $17 \mathrm{~L}$ & Low flux & Steam & PAES/PVP/PA & 1.7 & 12.5 & $3.1 \pm 0.2$ \\
\hline Revaclear 400 & High flux & Steam & PAES/PVP & 1.8 & 54.0 & $3.9 \pm 0.1$ \\
\hline Theranova 400 & Medium cut off & Steam & PAES/PVP & 1.7 & 48.0 & $5.0 \pm 0.1$ \\
\hline Theralite 2100 & High cut off & Steam & PAES/PVP & 2.1 & 52.0 & $10 \pm 2$ \\
\hline
\end{tabular}

PAES polyarylethersulfone, PVP polyvinylpyrrolidone, PA polyamide, UF ultrafiltration aeffective Stokes-Einstein radius: calculated from molecular weight cut-off measured with polydisperse Dextrane

\section{Dialysate and blood substitution fluids}

Ultrapure dialysis fluid was prepared on-line with an AK200 dialysis machine (Gambro, Lund, Sweden) using a smartbag ${ }^{\circ}$ (Fresenius Medical Care, Willebroek, Belgium) acid concentrate and a $\mathrm{BiCart}^{\mathrm{tm}}$ cartridge (Gambro) resulting in a dialysate containing $3 \mathrm{mM} \mathrm{K}$, $140 \mathrm{mM} \mathrm{Na}{ }^{+}, 1.25 \mathrm{mM} \mathrm{Ca}{ }^{2+}, 0.50 \mathrm{mM} \mathrm{Mg}^{2+}$ and $34 \mathrm{mM}$ bicarbonate.

A $1.25 \%$ polyvinylpyrrolidone (PVP) (Luvitec ${ }^{\circ}$ K85 powder, BASF, New Jersey, USA) solution was prepared in sterile PBS 10×, pH 7.2 (Gibco, Life technologies, Paisley, UK) and diluted 1:10 in sterile water (Braun, Melsungen, Germany) to achieve a solution with a kinematic viscosity of $4 \mathrm{~mm}^{2} / \mathrm{s}$, to mimic the viscosity of whole blood [34]. Viscosity was verified with an Ubbelohde Capillary Viscometer avs310 (SCHOTT Instruments, Weilheim, Germany). For each experiment, $3 \mathrm{~L}$ of this solution was prepared and recirculated through the blood compartment of the dialyzer.

Compatibility of PVP dissolved in PBS ( $\mathrm{PVP}_{\mathrm{PBS}}$ ) with both the LAL-assay and THP-1 assay was evaluated per se and in combination with LPS in comparison to PBS. No interference of the PVP dissolved in PBS could be observed in both assays.

\section{Challenge solution}

The ISO11663:2014 standard for LPS allows less than $0.5 \mathrm{EU} / \mathrm{mL}$ in dialysis fluid [26]. In the in vitro experimental set-up, the duration of a dialysis session was set to $1 \mathrm{~h}$. Corresponding to the total exposure during a regular dialysis session of $4 \mathrm{~h}$ a minimum endotoxin load of $2 \mathrm{EU} / \mathrm{ml}$ should be aimed for. However, to create a worst case scenario, this load was increased, aiming at a dialysis fluid containing at least $4 \mathrm{EU} / \mathrm{ml}$. To obtain this, a concentrated solution $(200 \mathrm{EU} / \mathrm{ml})$ of two clinically relevant water-borne bacterial species, Pseudomonas aeruginosa and Pelomonas saccharophila (BCCM/LMG, Gent, Belgium), was prepared [35, 36]. Both strains were cultured separately to a final concentration of $5.0 \times$ $10^{10} \mathrm{CFU} / \mathrm{ml}$ for $P$. aeruginosa and $3.3 \times 10^{10} \mathrm{CFU} / \mathrm{ml}$ for $P$. saccharophila, and harvested. The bacteria were treated with heat $\left(20 \mathrm{~min}, 95^{\circ} \mathrm{C}\right)$ followed by ultrasound (1 min, $10 \mathrm{rpm})$ to induce bacterial disintegration. The obtained lysates were combined as equal endotoxin units
(65,000 EU of $P$. aeruginosa plus $65,000 \mathrm{EU}$ of $P$. saccharophila) and diluted up to $50 \mathrm{ml}$ with dialysis fluid to a total concentration of $2600 \mathrm{EU} / \mathrm{ml}$. This solution was filtered [28-30, 32], with a Millex $33 \mathrm{~mm}$ Sterile Filter Unit with $0.45 \mu \mathrm{m}$ pore size Durapore ${ }^{\circ}$ membrane (Merck KGaA, Darmstadt, Germany) (1 filter per $10 \mathrm{ml}$ ) and further diluted up to $200 \mathrm{EU} / \mathrm{ml}$ with dialysis fluid. The solution was transferred to a sterile bag (Beldico, Marche-en-Famenne, Belgium) to be infused continuously into the dialysate circuit, aiming at a final concentration in the dialysate of $4 \mathrm{EU} / \mathrm{ml}$.

\section{Dialysis machine set-up}

The AK200 dialysis machine was set in double needle treatment and the tubings for hemodialysis (Gambro) and the dialyzers were connected. The different membranes were tested in random order as determined by an Excel based random generator; for each membrane type 6 different dialyzers were tested. The consecutive experimental steps are summarized in Table 2.

First the blood circuit of the dialyzer was primed with $0.9 \% \mathrm{NaCl}$ (Clear-flex, Baxter, Lessen, Belgium), followed by further priming of the dialysate circuit with ultrapure dialysis fluid. After discarding the priming solution, $1 \mathrm{~L}$ of human plasma (Octaplas, Octapharma, Langenfeld, Germany) was recirculated through the blood circuit side of the dialyzer with a bloodflow rate $\left(\mathrm{Q}_{\mathrm{B}}\right)$ of $200 \mathrm{ml} / \mathrm{min}$ at $37^{\circ} \mathrm{C}$ for $40 \mathrm{~min}$ with continuous mixing in the reservoir on a magnetic stirrer, in order to coat the membrane with plasma proteins [31, 37, 38]. During this procedure, the dialysate circuit was sealed off (dialysate flow rate $\left(Q_{D}\right)=0 \mathrm{ml} / \mathrm{min}$ ) and no ultrafiltration was allowed (ultrafiltration flow rate $\left(\mathrm{Q}_{\mathrm{F}}\right)=0 \mathrm{ml} / \mathrm{min}$ ). Afterwards the blood circuit was rinsed with PBS for $18 \mathrm{~min}$ at $\mathrm{a}_{\mathrm{B}}$ of $200 \mathrm{ml} / \mathrm{min}$ in isolated filtration mode (ultrafiltration $(\mathrm{UF})$ volume $=1.8 \mathrm{~L} / \mathrm{h}$ ). Then the PBS in the circuit was exchanged with the PVP solution.

During the actual experiment $3 \mathrm{~L}$ of the PVP solution at $37^{\circ} \mathrm{C}$ was recirculated during $60 \mathrm{~min}$ at a $\mathrm{Q}_{\mathrm{B}}$ of $400 \mathrm{ml} /$ min while the PVP pool was continuously mixed. The dialysate flow was set at $500 \mathrm{ml} / \mathrm{min}$ and the challenge solution was continuously infused from the sterile bag into the dialysate line before inlet of the dialyzer at a rate of $10 \mathrm{ml} /$ min with a droplet pump (Cardinal Health, Brussels, 
Table 2 Overview of the experimental steps of the in vitro dialysis

\begin{tabular}{|c|c|c|c|c|c|c|c|}
\hline Experimental Step & Solution Blood side & Circulation blood side & Time (min) & $\mathrm{Q}_{B}(\mathrm{ml} / \mathrm{min})$ & $\mathrm{Q}_{\mathrm{D}}(\mathrm{ml} / \mathrm{min})$ & $\mathrm{Q}_{\mathrm{F}}(\mathrm{ml} / \mathrm{min})$ & $\begin{array}{l}\text { Infusion } \\
\text { Contaminant }\end{array}$ \\
\hline Priming Blood circuit & $\mathrm{NaCl}$ & Discard & 5 & $100 \mathrm{ml} / \mathrm{min}$ & 0 & 0 & none \\
\hline Priming Dialysate circuit & None & - & 2 & 0 & 500 & 0 & none \\
\hline Exchange fluid in Blood circuit & Plasma & Discard & $\sim 2^{\mathrm{a}}$ & 200 & 0 & 0 & 0 \\
\hline Coating & Plasma & Recirculate & 40 & 200 & 0 & 0 & 0 \\
\hline Rinsing & PBS $1 \times$ & Discard & 18 & 200 & 0 & 30 & 0 \\
\hline Exchange fluid in Blood circuit & PVP & Discard & $\sim 2^{\mathrm{a}}$ & 200 & 0 & 0 & 0 \\
\hline Dialysis & PVP & Recirculate & 60 & 400 & 500 & 0 & $10 \mathrm{ml} / \mathrm{min}$ \\
\hline
\end{tabular}

atime depends on volume of circuit + membrane. For Polyflux: 1'56"; Revaclear: 1'53"; Theranova: 1'52"; Theralite: 2'07"

Belgium), aiming at a contamination level of the dialysate above $4 \mathrm{EU} / \mathrm{ml}$. A sampling port was placed between the contamination inlet port and the inlet of the dialyzer to assess the level of contamination. A schematic figure of the experimental set-up is shown in Fig. 1.

Samples of the dialysate were taken after 5 and 55 min. The PVP pool was sampled in duplicate before the start $\left(\mathrm{PVP}_{\text {start }}\right)$ and at the end $\left(\mathrm{PVP}_{\text {post }}\right)$ of the experiment. For the $\mathrm{PVP}_{\text {post }}$ solutions the LAL activity of the duplicates is reported separately, but the sample was considered positive for endotoxin if at least one contained a measurable endotoxin level. All samples were stored in pyrogen free glass tubes (Lonza, Walskersville,
MD, USA). For the endotoxin quantification, samples were stored at $4{ }^{\circ} \mathrm{C}$ for a maximum of $24 \mathrm{~h}$; for the cytokine induction assay samples were stored at $-20{ }^{\circ} \mathrm{C}$ until analysis.

For decalcification and disinfection of the dialysis machine fluid path, a CleanCart $\mathrm{C}^{\bullet}$ (Gambro) cartridge was used in combination with a heat disinfection program after each experiment. For each experiment a new set of tubings was used.

\section{Endotoxin quantification}

For quantification of intact LPS in the challenge solution, the dialysate and the PVP, the LAL test, a

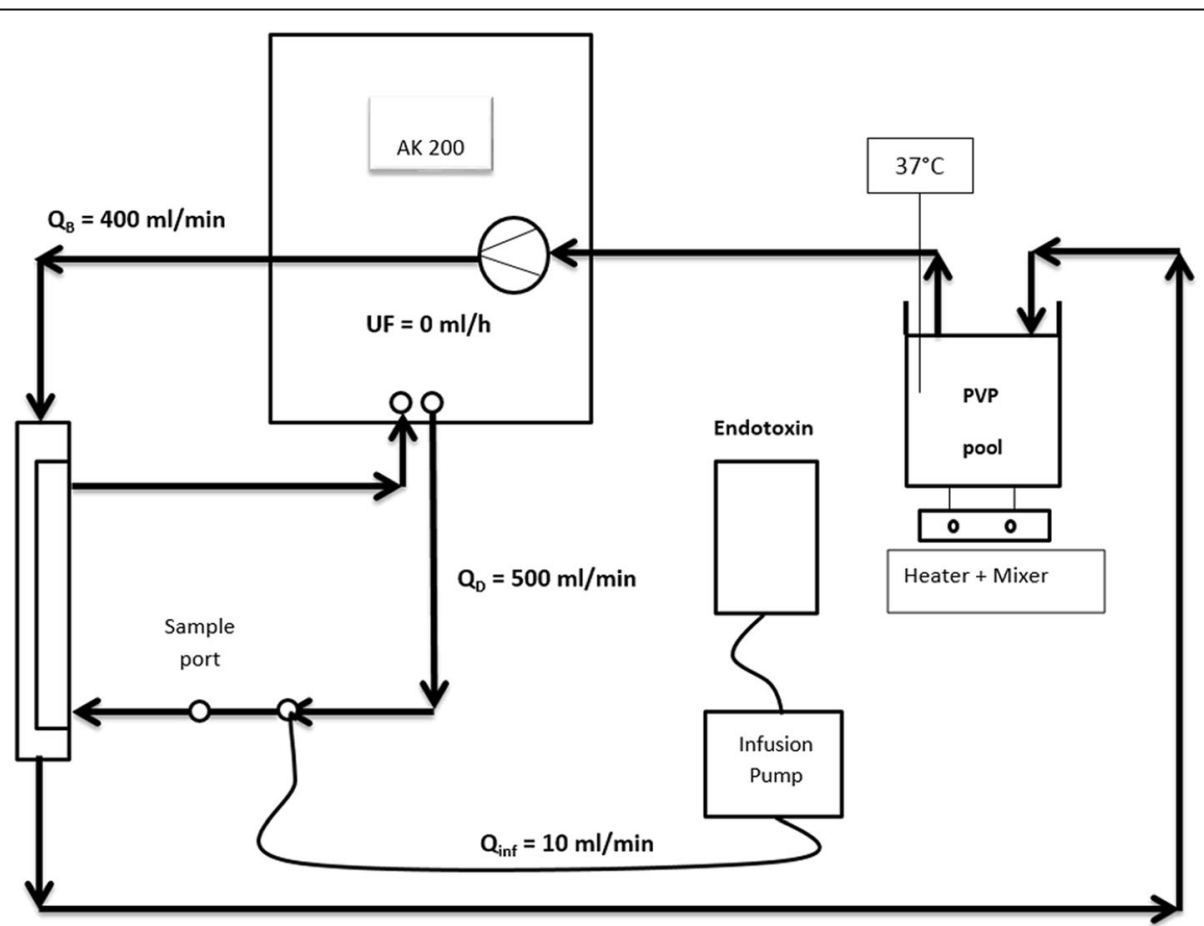

Fig. 1 Schematic overview of the dialysis set-up. After priming both blood and dialysate circuit and after coating the test membrane with plasma, $3 \mathrm{~L}$ of PVP solution, continuously mixed, was recirculated at $37^{\circ} \mathrm{C}$ at the blood side at a blood flow rate $\mathrm{Q}_{B}$ of $400 \mathrm{ml} / \mathrm{min}$. Samples of the PVP were taken from the pool before and after the experiment. The dialysate was prepared by the AK200 and circulated at a flow $Q_{D}$ of $500 \mathrm{ml} / \mathrm{min}$. Before entering the membrane contaminant was infused at a flow $Q_{\text {inf }}$ of $10 \mathrm{ml} / \mathrm{min}$ by means of a pump. Samples from the dialysate were taken just before the membrane at 5 and $55 \mathrm{~min}$. Ultrafiltration $\mathrm{Q}_{\mathrm{F}}$ was set at $0 \mathrm{ml} / \mathrm{min}$ 
quantitative kinetic and chromogenic assay (Kinetic$\mathrm{QCL}^{\circ}$ ) (Lonza), was used. The detection limit of this assay is $0.005 \mathrm{EU} / \mathrm{ml}$. The test was applied according to the manufacturer's guidelines.

\section{Cytokine induction assay with a THP-1 cell line}

To evaluate the biological activity of potential contamination in the tested solutions, the THP-1 assay was used as described previously [27].The human monocytic cell line THP-1 (ATCC, LGC, Promochem, Middlesex, UK) was maintained as a continuous culture. Cell cultures at a density of $1 \times 10^{6}$ cells $/ \mathrm{ml}$ were differentiated with calcitriol (10 nM; Sigma-Aldrich, St Louis, MO, USA) for $72 \mathrm{~h}$. Afterwards the medium was refreshed, followed by a $24 \mathrm{~h}$ rest period. The differentiated THP-1 cells were incubated in a 1:1 dilution (with a total volume of $700 \mu \mathrm{l}$ ) with the test solutions (dialysate, $\mathrm{PVP}_{\text {pre }}$ and $\left.\mathrm{PVP}_{\text {post }}\right)$ in polystyrene, pyrogen-free culture plates (Nunc, Roskilde, Denmark) for $24 \mathrm{~h}$ in a humidified atmosphere of $5 \% \mathrm{CO}_{2}$ at $37^{\circ} \mathrm{C}$. A sample of the cell culture medium was included as a negative control and 25 EU/ml LPS (E. coli 055:B5; Lonza) in PBS was included as a positive control. After incubation, the culture suspensions were collected and stored at $-20{ }^{\circ} \mathrm{C}$. After a centrifugation step ( $5 \mathrm{~min}, 3000 \mathrm{rpm}$ ) IL- $1 \beta$ was quantified in the culture supernatant using a sandwich ELISA kit (Quantikine, R\&D Systems, Abingdon, UK) according to manufacturer's guidelines.

\section{Logarithmic retention value}

As a measure of endotoxin retention capacity the logarithmic retention value (LRV) for each of the membranes was calculated using the following equation:

$$
L R V=\log _{10} \frac{\text { Endotoxin }^{\text {Dialysate }_{51}+\text { Dialysate }_{55 t}}}{2}
$$

\section{Statistics}

Data are expressed as mean \pm SD. Measurements below the limit of detection of the LAL-assay were replaced by the LOD $/ \sqrt{ } 2$ [39]. Statistical analysis was performed using a One-way ANOVA or an unpaired T-test using GraphPad Prism 4.0. A $p$-value of less than 0.05 was considered significant.

\section{Results}

\section{Assay compatibility of PVP}

PVP dissolved in PBS (PVP $\mathrm{PBS}_{\mathrm{P}}$ ) at a concentration of $12.5 \mathrm{~g} / \mathrm{L}$ was evaluated for its possible interference with both the LAL-assay and the THP-1 assay. In the LALassay, $\mathrm{PBS}$ and $\mathrm{PVP}_{\mathrm{PBS}}$ were tested per se and as a dose re-

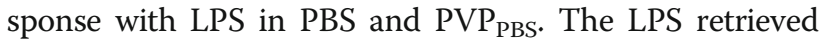

with the LAL-assay was within the acceptable range of $50 \%-200 \%$ of the added concentration (data not shown) [40]. In the THP-1 assay, PBS and $\mathrm{PVP}_{\mathrm{PBS}}$ were evaluated per se and in combination with $45 \mathrm{EU} / \mathrm{ml}$ LPS. THP-1 cells did not produce IL-1 $\beta$ in the presence of PBS and $\mathrm{PVP}_{\mathrm{PBS}}$, but when LPS was added the cytokine expression was comparable to the response of LPS dissolved in PBS as such (data not shown). Thus the combination of PVP dissolved in PBS does neither interfere with the results of the LAL nor with the THP-1 assay.

\section{Permeability of dialysis membranes for bacterial filtrates}

Table 3 shows the individual and the mean LAL assay responses for the dialysate and PVP solutions per individual experiment, categorized per membrane.

Although dialysate-endotoxin concentration varied between 3.2 and $33.7 \mathrm{EU} / \mathrm{ml}$ in the individual experiments, mainly due to the difficulty of filtrate preparation and complexity of the experimental set-up, the mean exposure to endotoxins through the contaminated dialysate was above the intended minimum $4 \mathrm{EU} / \mathrm{ml}$ for each of the different experiments and did not differ between the different membranes. No correlation was found between endotoxin load and permeability.

LAL activity in the PVP solution at the blood side of the dialyzer was below the limit of detection (LOD = $0.005 \mathrm{EU} / \mathrm{ml})$ both before $\left(\mathrm{PVP}_{\mathrm{pre}}\right)$ and after the experiment $\left(\mathrm{PVP}_{\text {post }}\right)$ for 12 out of 24 tested dialyzers. Endotoxin levels were below LOD in all but three $\mathrm{PVP}_{\text {pre }}$ solutions. This potentially indicates contamination occurred already before the start of the experiment in these three experiments. Positive $\mathrm{PVP}_{\text {post }}$ reading higher than the corresponding $\mathrm{PVP}_{\text {pre }}$ reading, indicating possible contamination from endotoxin in the dialysate, was found in 9 out of 24 experiments (low-flux: 1/6; highflux: 1/6; MCO 3/6; HCO: 4/6) however, there was no apparent correlation between the individual endotoxin challenge concentrations and the detectable readings and in three of these cases only one of the duplicate tests was positive.

\section{Logarithmic retention value}

Using the LAL-data as measured above, the LRV values vary from $3.09 \pm 0.50$ for $\mathrm{HCO}$ membranes over $3.16 \pm 0.29$ and $3.21 \pm 0.28$ and for low-flux and MCO membranes respectively to $3.29 \pm 0.46$ for the high flux membranes. No statistical differences were found between the four membrane types.

\section{Cytokine induction assay}

As shown in Table 4, $25 \mathrm{EU} / \mathrm{ml}$ LPS and the contaminated dialysate significantly induced IL- $1 \beta$ expression, whereas none of the PVP solutions used in the different experiments induced IL-1 $\beta$ expression neither before or at the 
Table 3 Endotoxin levels in the dialysate and the PVP solution per membrane measured by the LAL-assay ( $n=6$ for each membrane). LOD was $0.005 \mathrm{EU} / \mathrm{ml}$

\begin{tabular}{|c|c|c|c|c|c|}
\hline \multirow[t]{2}{*}{ Membrane } & \multirow{2}{*}{$\begin{array}{l}\text { Dialysate } \\
(\mathrm{EU} / \mathrm{ml})\end{array}$} & \multirow{2}{*}{$\begin{array}{l}P V P_{\text {pre }} \\
(E \cup / m l)\end{array}$} & \multicolumn{2}{|c|}{$\mathrm{PVP}_{\text {post }}(\mathrm{EU} / \mathrm{ml})$} & \multirow{2}{*}{$\begin{array}{l}\text { Statistics } \\
\text { PVP pre VS } \\
\text { PVP post }\end{array}$} \\
\hline & & & $\begin{array}{l}\text { Duplicate } \\
1\end{array}$ & $\begin{array}{l}\text { Duplicate } \\
2\end{array}$ & \\
\hline \multirow[t]{6}{*}{ Low-flux } & 3.5 & $<\mathrm{LOD}$ & $<\mathrm{LOD}$ & $<\mathrm{LOD}$ & \\
\hline & 3.9 & $<\mathrm{LOD}$ & $<\mathrm{LOD}$ & $<\mathrm{LOD}$ & \\
\hline & 5.5 & $<\mathrm{LOD}$ & $<\mathrm{LOD}$ & $<\mathrm{LOD}$ & \\
\hline & 9.4 & $<\mathrm{LOD}$ & $<L O D$ & $<\mathrm{LOD}$ & \\
\hline & 10.3 & $<\mathrm{LOD}$ & 0.011 & $<\mathrm{LOD}$ & \\
\hline & 19.1 & $<L O D$ & $<\mathrm{LOD}$ & $<\mathrm{LOD}$ & n.s. \\
\hline Mean \pm SD & $8.6 \pm 5.8$ & & & & \\
\hline \multirow[t]{6}{*}{ High-flux } & 3.6 & $<\mathrm{LOD}$ & $<\mathrm{LOD}$ & $<\mathrm{LOD}$ & \\
\hline & 4.1 & 0.008 & 0.007 & 0.008 & \\
\hline & 5.9 & $<\mathrm{LOD}$ & $\underline{0.005}$ & $<\mathrm{LOD}$ & \\
\hline & 6.1 & $<\mathrm{LOD}$ & $<\mathrm{LOD}$ & $<\mathrm{LOD}$ & \\
\hline & 20.0 & 0.007 & $<\mathrm{LOD}$ & $<\mathrm{LOD}$ & \\
\hline & 33.7 & $<\mathrm{LOD}$ & $<\mathrm{LOD}$ & $<\mathrm{LOD}$ & n.s. \\
\hline Mean \pm SD & $12.2 \pm 12.2$ & & & & \\
\hline \multirow[t]{6}{*}{ Medium cut-off } & 6.0 & $<\mathrm{LOD}$ & $\underline{0.023}$ & $\underline{0.005}$ & \\
\hline & 6.3 & $<\mathrm{LOD}$ & $<\mathrm{LOD}$ & $<\mathrm{LOD}$ & \\
\hline & 6.8 & $<\mathrm{LOD}$ & $<\mathrm{LOD}$ & $<\mathrm{LOD}$ & \\
\hline & 8.0 & $<\mathrm{LOD}$ & $\underline{0.006}$ & $\underline{0.005}$ & \\
\hline & 10.6 & $<\mathrm{LOD}$ & $\underline{0.005}$ & $\underline{0.005}$ & \\
\hline & 11.8 & $<\mathrm{LOD}$ & $<\mathrm{LOD}$ & $<\mathrm{LOD}$ & n.s. \\
\hline Mean \pm SD & $8.3 \pm 2.4$ & & & & \\
\hline \multirow[t]{6}{*}{ High cut-off } & 3.2 & $<\mathrm{LOD}$ & $\underline{0.019}$ & $\underline{0.013}$ & \\
\hline & 4.1 & $<\mathrm{LOD}$ & $\underline{0.005}$ & $\underline{0.005}$ & \\
\hline & 5.4 & $<\mathrm{LOD}$ & $\underline{0.005}$ & $\underline{0.005}$ & \\
\hline & 5.8 & $<\mathrm{LOD}$ & $\underline{0.005}$ & $<\mathrm{LOD}$ & \\
\hline & 12.1 & $<\mathrm{LOD}$ & $<\mathrm{LOD}$ & $<\mathrm{LOD}$ & \\
\hline & 22.5 & 0.006 & 0.005 & 0.005 & n.s. \\
\hline Mean \pm SD & $8.9 \pm 7.4$ & & & & \\
\hline
\end{tabular}

Data with measurable endotoxin levels were written in italic and when they were higher than the PVPpre value they were additionally put in bold and underlined end of the experiments. Moreover, no significant difference in induction of IL- $1 \beta$ expression was found between the PVP solutions treated with the different membranes.

\section{Discussion}

In the present study a new, clinically more representative model to test permeability of dialyzers for endotoxins is demonstrated. It is to our knowledge the first time that permeability of membranes was tested using a relevant, realistic set-up mimicking real life settings and conditions. Using this set-up, four dialysis membranes of comparable composition but with different pore size were tested for their permeability for endotoxins by exposing them during a $1 \mathrm{~h}$ in vitro dialysis session to dialysate contaminated with filtrates of two water-borne bacteria, $P$. aeruginosa and $P$. saccharophila, at an endotoxin challenge at least four times the upper limit of endotoxin load $(2 \mathrm{EU} / \mathrm{ml})$ when using standard dialysis fluid [26]. For the tested membranes, there was a nonsignificant difference in number of the PVP solutions which contained a detectable amount of endotoxin after repetitive circulation through the dialyzer, be it close to the detection limit in the majority of cases. It was chosen to give the individual data from all experiments as this is the most exact way to present the data and to give the reader full visibility of the data. The PVP solutions in many cases had a measured LAL activity below the LOD and the individual numbers give a better impression of the limited degree of contamination in case values were above LOD in the blood compartment. It might be speculated that increasing the number of experimental repeats could lead to statistical significance in the differences between the membranes, however this will not change the clinical relevance of the low degree of contamination. Interestingly, there was no doseresponse correlation between the level of contamination within the tested range of dialysate endotoxin concentration and the detectable concentration of endotoxin in the $\mathrm{PVP}_{\text {post }}$ solutions, neither across the whole data set (all tested dialyzers) nor in any of the individual data sets (the four membranes tested). None of the PVP solutions induced measurable IL-1 $\beta$ expression in the THP-1 assay, and there was no difference in the logarithmic retention values as based on the measured LAL-levels, and

Table 4 Overview of IL-1 $\beta$ expression in $\mathrm{pg} / \mathrm{ml}$ in the THP-1 cytokine induction assay by the dialysate and PVP solutions

\begin{tabular}{lllllll}
\hline & Medium & LPS 25EU/ml & Dialysate & PVP pre & PVP post & Statistics \\
\hline Low-flux & $11.44 \pm 4.05$ & $53.78 \pm 21.11^{*}$ & $51.69 \pm 57.07$ & $10.87 \pm 4.02$ & $10.53 \pm 4.22$ & n.S. \\
High-flux & $12.86 \pm 3.43$ & $62.03 \pm 22.91^{*}$ & $88.4 \pm 122.13$ & $11.87 \pm 3.09$ & $11.09 \pm 2.82$ & n.s. \\
Medium cut-off & $11.93 \pm 3.54$ & $54.71 \pm 20.85^{*}$ & $40.99 \pm 60.49$ & $12.11 \pm 3.55$ & $11.13 \pm 2.87$ & n.s. \\
High cut-off & $12.25 \pm 3.69$ & $59.97 \pm 17.22^{*}$ & $22.78 \pm 21.88$ & $11.55 \pm 3.69$ & $11.30 \pm 3.18$ & n.s. \\
\hline
\end{tabular}

${ }^{*} p<0.05$ vs Medium; ${ }^{\circ}$ PVPpre vs. PVPpost 
for none of the devices the LAL activity changed significantly PVPpost vs. PVPpre.

Over the last years, membranes with larger pore sizes, such as $\mathrm{MCO}$ and $\mathrm{HCO}$, have been introduced in an attempt to reduce inflammation and cardiovascular toxicity in patients with ESKD by an enhanced clearance of middle molecular weight substances during dialysis. Several trials have meanwhile provided evidence suggesting that larger pore membranes indeed enhance clearance of different middle molecules, and can reduce inflammation and calcification. A study in hemodialysis patients treated with $\mathrm{HCO}$ vs. high-flux membranes demonstrated by exposing THP-1 monocytes their serum or to the dialysate that $\mathrm{HCO}$ membranes eliminate a spectrum of pro-inflammatory mediators from serum into the dialysate [41]. In patients with signs of chronic mild inflammation (C-reactive protein $(\mathrm{CRP})>5 \mathrm{mg} / \mathrm{l})$, use of $\mathrm{HCO}$ in series with a low-flux dialyzer resulted in a dampening of systemic inflammation markers such as soluble TNF receptor 1 (sTNFR1), associated with (cardiovascular) outcomes in observational CKD cohorts [42], but not of expression density of the P-selectin receptor CD162 on monocytes in pre-dialysis blood samples [15]. In an unblinded randomized cross over study comparing hemodialysis of equal duration using a high-flux vs. an MCO membrane during 4 weeks each, pre-dialysis TNF- $\alpha$ and IL- 6 mRNA expression levels in white blood cells were reduced when using MCO compared to conventional high flux, but no effect was observed on CRP levels [23]. In addition, TNFR1 and kappa and lambda free light chains serum levels were reduced more effectively by MCO. Unfortunately, these studies did not assess actual removal of these substances, so it remains unclear whether the effects were due to reduced production or to enhanced clearance of the retention products. Also, it is remarkable that the effect of using larger pores only influenced levels of some and not all cytokines, despite them having the same range of molecular weight. This might point to differences in distribution volume, or in generation rate.

These studies, while promising, still refer to surrogate markers assessed. So far, no study of the impact of MCO or HCO membranes on patient relevant (hard) endpoints, such as mortality, cardiovascular events or even quality of life has been performed. The clinical benefits of the use of $\mathrm{MCO}$ and $\mathrm{HCO}$, while promising, thus still need further underpinning.

Upregulation of production of cytokines by the use of the larger pore size membranes might be of concern when their usage would result in pro-inflammatory factors by transmigration of contaminants from the dialysate side. So far, all of the above mentioned studies have been performed in a setting where ultrapure dialysate was used. If the use of larger pore membranes would result in a substantial transmembrane transport of bacterial degradation products in settings with poor water quality, the positive effects of this type of membranes on inflammation could potentially be completely annihilated by the added inflammatory burden induced by these translocated contaminants. A case-study by Gong et al. reported a risk for endotoxemia when using an $\mathrm{HCO}$ membrane in combination with conventional dialysis fluid $(0.112-0.141 \mathrm{EU} / \mathrm{ml})$ [43]. However these results rely on a single measurement and as reviewed by Wong et al. caution should be taken when measuring endotoxin levels in blood using the LAL assay as its sensitivity and specificity for biological samples is poor [44]. The present experiments demonstrate that, when using a 4-fold overload of endotoxin, the use of larger pore membranes, $\mathrm{MCO}$ and $\mathrm{HCO}$, is likely safe from that regard. Indeed, in none of the experiments, biological activation of the inflammatory system was observed as measured by a IL-1 $\beta$ production by the THP1-assay, sensitive for several bacterial components such as intact LPS, LPS fragments, peptidoglycan and short bacterial DNA fragments [27]. In the majority of experiments, no measurable transmembrane migration of endotoxin took place. The highest measured level of endotoxin in a duplicate sample from the 'patient side' was $0.023 \mathrm{EU} / \mathrm{ml}$. This corresponds to a total amount of about $70 \mathrm{EU}$ transferred during the $1 \mathrm{~h}$ dialysis session, and thus a transfer rate of about $1 \mathrm{EU} / \mathrm{kg} / \mathrm{h}$ (mean patient of $70 \mathrm{~kg}$ ), which is still well below the pyrogenicity limit of $5 \mathrm{EU} /$ $\mathrm{h} / \mathrm{kg}$ body weight (the minimum dose that induces fever) for injectable medications and devices [26].

Of note, our experimental set-up is a worst case scenario in which endotoxin exposure is 4-fold greater than permitted in standard (not ultrapure!) dialysate, spread over a $4 \mathrm{~h}$ dialysis session. It is of note that most modern dialysis monitors have an additional ultrafilter between permeate and dialysate, providing an extra safeguard for contamination that was bypassed in our set-up infusing the contaminant at the dialyzer inlet. Our results demonstrate that in facilities where water quality is within ISO standards of regular dialysate quality, the risk for cross-contamination of the blood side by endotoxins from the dialysate side when using membranes with larger pores is limited. In this type of setting, and by extension of course also in the setting of ultrapure dialysate, use of large pore membranes can potentially result in a dampening of chronic micro-inflammation. Larger longterm clinical trials with patient relevant outcomes are warranted to evaluate this hypothesis.

Special emphasis was made in the present study to develop an experimental model mimicking the clinical reality as close as possible. In the setting of the investigation of transmembrane migration of endotoxins from the dialysate to the blood side of the dialyzer, it is also 
important to keep in mind that this migration can not only take place by diffusion, but also by backfiltration. Backfiltration of contaminants can be influenced by properties of the membrane, such as pore size, surface area, and geometrical configuration of the fibers; by ultrafiltration rates, and thus by the hydraulic set-up of the dialysate circuit; by the viscosity of the solution circulating at the blood side of the membrane $[45,46]$. Therefore, it was opted to use full size dialyzers rather than down-sized models, and these were assembled on a dialysis monitor as used in daily clinical practice, rather than using separate pumps to circulate the dialysate and the surrogate blood solution. Furthermore, to exclude confounding by differences in polymers, dialyzers of comparable membrane composition from a single manufacturer were chosen to focus on the investigation of variation in pore size. Therefore, the results of our investigation can likely not be generalized to membranes of different compositions or structure. The dialysate and blood flows were comparable to the ones applied in the clinic and in the same context, viscosity of the fluid circulating in the blood compartment was comparable to that of blood, mimicking clinical pressure distributions in the dialyzer and with it, realistic filtration profiles. To create a worst-case scenario ultrafiltration was set at $0 \mathrm{ml} / \mathrm{min}$, resulting in a maximal backfiltration. It was opted not to use whole blood for the experiments since this is indeed cumbersome and expensive. In addition, concerns have been raised in the past that the use of whole blood in this type of experimental set up might abrogate activity of endotoxins as several components of whole blood have the capacity to neutralize endotoxins. The use of whole blood would thus potentially result in a false negative results when endotoxin transfer is being investigated [47].

Further, it was opted to apply a protein coating to the tested membranes by circulating a human plasma solution before the beginning of the experiments in order to mimic the properties of the synthetic membranes during dialysis, [37]. The differences in membrane properties after contact with blood can be attributed to the adhesion of proteins to the membrane surface, and is related to the membrane material $[38,48,49]$. A protein layer, also referred to as secondary layer, is created on top of the membrane due to the adhesion of proteins to the membrane surface, and acts also as a barrier for the transport of substances. It is known to be a process that is not instantaneous [49], but that occurs during the first hour of treatment [48]. This phenomenon cannot be described with the PVP model solution since the PVP molecules are unlikely to adsorb to the membrane surface. The coating is important with respect to biocompatibility in vivo [50], but it also decreases transport through the membrane and in this way also backfiltration of contaminants [37].
Finally, it is also important to use a relevant inoculum to create the endotoxin load. Sterile filtrates of $P$. aeruginosa and $P$. saccharophila were used as source of endotoxins, as they are relevant water-borne bacteria retrieved in dialysis circuits [36]. Preparations of bacteria can contain a wide range of contaminants and endotoxins with different molecular weight and thus different properties with regards to transmembrane transport. Not all of these bacterial products might test positive in the LAL test, but they do have a cytokine inducing capacity as assessed by the production of IL- $1 \beta$ by the THP1 cell line in the bio-assay. Considering all these issues, the model presented here is very close to the clinical reality, adding more weight to the results and observations shown.

Remarkably, none of the PVP solutions induced a biological response as assessed by activity of human THP-1 monocytes higher than that of the background culture medium, despite the fact that in some of the PVP samples endotoxin was detectable. As demonstrated by Glorieux et al., the THP-1 assay only induces a significant increase in IL-1 $\beta$ expression in the presence of $0.1 \mathrm{ng} / \mathrm{mL}$ LPS $(1.25 \mathrm{EU} / \mathrm{ml})$, comparable to the response of monocytes in healthy blood [27]. So based on the endotoxin levels quantified by the LAL-test, no induction of IL-1beta expression is to be expected. In contrast to the LAL-test, the THP1assay reacts to more than endotoxin alone, suggesting that levels of other possible bacterial degradation products were also in the lower range.

\section{Conclusions}

A realistic and feasible model to assess dialysis membrane translocation of bacterial degradation products present in the dialysate was developed and applied to test the retention capacity of 4 different membranes with similar chemical composition but different pore sizes. Although more blood side PVP solutions had a detectable amount of endotoxin using a highly sensitive LAL assay in the more open vs traditional membranes the permeability for endotoxins of the 4 tested dialysis membranes was not significantly different. Moreover, none of these PVP ${ }_{\text {post }}$ solutions induced IL- $1 \beta$ expression in the THP-1 based bio-assay that is sensitive also to other bacterial byproducts.

\footnotetext{
Abbreviations

CFU: Colony forming units; CRP: C-reactive protein; ESKD: End stage kidney disease; EU: Endotoxin units; HCO: High cut-off; HD: Hemodialysis; IL1 $\beta$ : Interleukin-1 $\beta$; ISO: International Organization for Standardization; LAL: Limulus Amebocyte Lysate; LOD: Limit of detection; LPS: Lipopolysaccharide; LRV: Logarithmic retention volume; MCO: Medium cut-off; PVP: Polyvinylpyrrolidone; PVPPBS: PVP dissolved in PBS; PVPpost: PVP after the experiment; PVPpre: PVP before the experiment; QB: Blood flow rate; QD: Dialysate flow rate; QUF: Ultrafiltration flow rate; sTNFR1: Soluble TNF receptor 1; TNF-a: Tumor necrosis factor $\alpha$; UF: Ultrafiltration; $\beta 2 \mathrm{M}$ : $\beta 2-$ microglobulin
} 


\section{Acknowledgements}

We greatly appreciate M. Glasebach, E. Loeffler, J. Calus and B. Vaeyens for their technical support with the handling of the AK200 dialysis machine and S. Lobbestael for the help in performing the LAL-assays and THP-1 assays. Data presented here were partially published in abstract format in Nephrology Dialysis Transplantation as part of the 53th ERA-EDTA Congress (Nephrol Dial Tranpl 2017; 32(suppl 3):iii625-iii626).

\section{Funding}

The present study was supported by a research grant from Baxter received by W. Van Biesen. The dialysis membranes (Polyflux $17 \mathrm{~L}$, Revaclear 400, Theranova 400 and Theralite ${ }^{T M} 2100$ ) were provided by Baxter, Hechingen, Germany.

\section{Availability of data and materials}

Part of the data generated and/or analysed during this study are included in this publication. The other datasets are available from the corresponding author upon request.

\section{Authors' contributions}

$E S, G G, S E, M H, A B, B K$ and $W V B$ designed the study. ES and GG performed the dialysis sessions, LAL-assays and THP-1 assays. ES, GG, SE, MH, AB, WB and $\mathrm{WVB}$ were involved in the data interpretation. $\mathrm{ES}, \mathrm{GG}$, SE and WVB wrote the manuscript. All authors reviewed the manuscript.

\section{Ethics approval and consent to participate}

Not applicable

\section{Consent for publication}

Not applicable

\section{Competing interests}

M. Hulko, A Boschetti-de-Fierro, W. Beck and B. Krause are employees of Baxter International Inc. E. Schepers, G. Glorieux and S. Eloot declare no competing interests.

\section{Publisher's Note}

Springer Nature remains neutral with regard to jurisdictional claims in published maps and institutional affiliations.

\section{Author details}

'Department of Internal Medicine, Nephrology Division, Ghent University Hospital, Gent, Belgium. ${ }^{2}$ Baxter International Inc., R\&D, Hechingen, Germany.

\section{Received: 8 July 2017 Accepted: 21 December 2017}

\section{Published online: 05 January 2018}

\section{References}

1. Vanholder R, Massy Z, Argiles A, Spasovski G, Verbeke F, Lameire N. Chronic kidney disease as cause of cardiovascular morbidity and mortality. Nephrol Dial Transplant. 2005;20(6):1048-56.

2. Zimmermann J, Herrlinger S, Pruy A, Metzger T, Wanner C. Inflammation enhances cardiovascular risk and mortality in hemodialysis patients. Kidney Intl. 1999;55(2):648-58.

3. Vanholder R, De Smet R, Hsu C, Vogeleere P, Ringoir S. Uremic toxicity: the middle molecule hypothesis revisited. Semin Nephrol. 1994;14(3):205-18.

4. Cheung AK, Levin NW, Greene T, Agodoa L, Bailey J, Beck G, et al. Effects of high-flux hemodialysis on clinical outcomes: results of the HEMO study. J Am Soc Nephrol. 2003;14(12):3251-63.

5. Cheung AK, Rocco MV, Yan G, Leypoldt JK, Levin NW, Greene T, et al. Serum beta-2 microglobulin levels predict mortality in dialysis patients: results of the HEMO study. J Am Soc Nephrol. 2006;17(2):546-55.

6. Delmez JA, Yan G, Bailey J, Beck GJ, Beddhu S, Cheung AK, et al. Cerebrovascular disease in maintenance hemodialysis patients: results of the HEMO study. Am J Kidney Dis. 2006;47(1):131-8.

7. Locatelli F, Martin-Malo A, Hannedouche T, Loureiro A, Papadimitriou M, Wizemann $V$, et al. Effect of membrane permeability on survival of hemodialysis patients. J Am Soc Nephrol. 2009;20(3):645-54.

8. Meert N, Eloot S, Schepers E, Lemke HD, Dhondt A, Glorieux G, et al Comparison of removal capacity of two consecutive generations of high- flux dialysers during different treatment modalities. Nephrol Dial Transplant. 2011;26(8):2624-30.

9. Grooteman MP, van den Dorpel MA, Bots ML, Penne EL, van der Weerd NC, Mazairac AH, et al. Effect of online hemodiafiltration on all-cause mortality and cardiovascular outcomes. J Am Soc Nephrol. 2012;23(6):1087-96.

10. Maduell F, Moreso F, Pons M, Ramos R, Mora-Macia J, Carreras J, et al. Highefficiency postdilution online hemodiafiltration reduces all-cause mortality in hemodialysis patients. J Am Soc Nephrol. 2013;24(3):487-97.

11. Ok E, Asci G, Toz H, Ok ES, Kircelli F, Yilmaz M, et al. Mortality and cardiovascular events in online haemodiafiltration (OL-HDF) compared with high-flux dialysis: results from the Turkish OL-HDF study. Nephrol Dial Transplant. 2013;28(1):192-202.

12. Boschetti-de-Fierro A, Voigt M, Storr M, Krause B. Extended characterization of a new class of membranes for blood purification: the high cut-off membranes. Int J Artif Organs. 2013:36(7):455-63.

13. Haase M, Bellomo R, Baldwin I, Haase-Fielitz A, Fealy N, Morgera S, et al. Beta2-microglobulin removal and plasma albumin levels with high cut-off hemodialysis. Int J Artif Organs. 2007;30(5):385-92.

14. Kneis C, Beck W, Boenisch O, Klefisch F, Deppisch R, Zickler D, Schindler R. Elimination of middle-sized uremic solutes with high-flux and high-cut-off membranes: a randomized in vivo study. Blood Purif. 2013;36(3-4):287-94.

15. Girndt M, Fiedler R, Martus P, Pawlak M, Storr M, Bohler T, et al. High cut-off dialysis in chronic haemodialysis patients. Eur J Clin Investig. 2015:45(12): 1333-40.

16. Zickler D, Willy K, Girndt M, Fiedler R, Martus P, Storr M, Schindler R. High cut-off dialysis in chronic haemodialysis patients reduces serum procalcific activity. Nephrol Dial Transplant. 2016;31(10):1706-12.

17. Boschetti-de-Fierro A, Voigt M, Storr M, Krause BMCO. Membranes: enhanced selectivity in high-flux class. Sci Rep. 2015;5:18448.

18. Kirsch AH, Lyko R, Nilsson LG, Beck W, Amdahl M, Lechner P, et al. Performance of hemodialysis with novel medium cut-off dialyzers. Nephrol Dial Transplant. 2017:32(1):165-72.

19. Desjardins L, Liabeuf $S$, Lenglet A, Lemke HD, Vanholder R, Choukroun G, Massy ZA. Association between free light chain levels, and disease progression and mortality in chronic kidney disease. Toxins. 2013;5(11): 2058-73.

20. Assi LK, Mclntyre N, Fraser S, Harris S, Hutchison CA, Mclntyre CW, et al. The association between polyclonal combined serum free light chain concentration and mortality in individuals with early chronic kidney disease. PLoS One. 2015;10(7):e0129980.

21. Haynes R, Hutchison CA, Emberson J, Dasgupta T, Wheeler DC, Townend $J N$, et al. Serum free light chains and the risk of ESRD and death in CKD. Clin J Am Soc Nephrol. 2011;6(12):2829-37.

22. Hutchison CA, Burmeister A, Harding SJ, Basnayake K, Church H, Jesky MD, et al. Serum polyclonal immunoglobulin free light chain levels predict mortality in people with chronic kidney disease. Mayo Clin Proc. 2014;89(5): 615-22.

23. Zickler D, Schindler R, Willy K, Martus P, Pawlak M, Storr M, et al. Medium cut-off (MCO) membranes reduce inflammation in chronic dialysis patientsa randomized controlled clinical trial. PLoS One. 2017;12(1):e0169024.

24. Arizono K, Nomura K, Motoyama T, Matsushita Y, Matsuoka K, Miyazu R, et al. Use of ultrapure dialysate in reduction of chronic inflammation during hemodialysis. Blood Purif. 2004;22(Suppl 2):26-9.

25. Susantitaphong P, Riella C, Jaber BL. Effect of ultrapure dialysate on markers of inflammation, oxidative stress, nutrition and anemia parameters: a metaanalysis. Nephrol Dial Transplant. 2013;28(2):438-46.

26. Quality of dialysis fluid for haemodialysis and related therapies. ISO 11663: 2014(E) 2014.

27. Glorieux G, Schepers E, Schindler R, Lemke HD, Verbeke F, Dhondt A, et al, A novel bio-assay increases the detection yield of microbiological impurity of dialysis fluid, in comparison to the LAL-test. Nephrol Dial Transplant. 2009;24(2):548-54.

28. Lonnemann G, Behme TC, Lenzner B, Floege J, Schulze M, Colton CK, et al. Permeability of dialyzer membranes to TNF alpha-inducing substances derived from water bacteria. Kidney Int. 1992;42(1):61-8.

29. Lonnemann G, Sereni L, Lemke HD, Tetta C. Pyrogen retention by highly permeable synthetic membranes during in vitro dialysis. Artif Organs. 2001; 25(12):951-60.

30. Schindler R, Christ-Kohlrausch F, Frei U, Shaldon S. Differences in the permeability of high-flux dialyzer membranes for bacterial pyrogens. Clin Nephrol. 2003;59(6):447-54. 
31. Schindler R, Ertl T, Beck W, Lepenies J, Boenisch O, Oppermann M, et al. Reduced cytokine induction and removal of complement products with synthetic hemodialysis membranes. Blood Purif. 2006;24(2):203-11.

32. Weber V, Linsberger I, Rossmanith E, Weber C, Falkenhagen D. Pyrogen transfer across high- and low-flux hemodialysis membranes. Artif Organs. 2004;28(2):210-7.

33. Hulko M, Gekeler A, Koch I, Dietrich V, Krause B. Dialysis membrane pore size does not determine LPS retention. Nephrol Dial Transplant. 2015; 30(suppl 3)

34. Lowe GD, Lee AJ, Rumley A, Price JF, Fowkes FG. Blood viscosity and risk of cardiovascular events: the Edinburgh artery study. Br J Haemat. 1997;96(1): $168-73$.

35. Gomila M, Bowien B, Falsen E, Moore ER, Lalucat J. Description of Pelomonas aquatica sp. nov. and Pelomonas puraquae sp. nov., isolated from industrial and haemodialysis water. Int J Syst Evol Microbiol. 2007;57(Pt 11):2629-35

36. Gomila M, Gasco J, Busquets A, Gil J, Bernabeu R, Buades JM, Lalucat J. Identification of culturable bacteria present in haemodialysis water and fluid. FEMS Microbiol Ecol. 2005;52(1):101-14.

37. Eloot S, De Wachter D, Vienken J, Pohlmeier R, Verdonck P. In vitro evaluation of the hydraulic permeability of polysulfone dialysers. Int J Artif Organs. 2002;25(3):210-6

38. Kunas GA, Burke RA, Brierton MA, Ofsthun NJ. The effect of blood contact and reuse on the transport properties of high-flux dialysis membranes, ASAIO J. 1996;42(4):288-94.

39. Ogden TL. Handling results below the level of detection. Ann Occup Hyg. 2010;54(3):255-6.

40. Convention USP: General Chapter <85> Bacterial Endotoxins Test. In: United States Pharmacopeia [USP]. edn.

41. Trojanowicz B, Ulrich C, Fiedler R, Storr M, Boehler T, Martus P, et al. Impact of serum and dialysates obtained from chronic hemodialysis patients maintained on high cut-off membranes on inflammation profile in human THP-1 monocytes. Hemodial Int. 2017;21(3):348-58.

42. Neirynck N, Glorieux G, Schepers E, Verbeke F, Vanholder R. Soluble tumor necrosis factor receptor 1 and 2 predict outcomes in advanced chronic kidney disease: a prospective cohort study. PLoS One. 2015;10(3):e0122073.

43. Gong D, Ji D, Zhang K, Huang X, Huang G, Xu B, Liu Z. Endotoxemia after high cutoff hemodialysis for treatment of patient with multiple myeloma can be prevented by using ultrapure dialysate: a case report. Hemodial Int. 2013;17(4):618-23.

44. Wong J, Vilar E, Farrington K. Endotoxemia in end-stage kidney disease. Semin Dial. 2015;28(1):59-67.

45. Ronco C. Fluid mechanics and Crossfiltration in hollow-fiber Hemodialyzers. In: Ronco C, Canaud B, Aljama P, editors. Hemodiafiltration, vol. 158. Basel: Karger; 2007. p. 34-49.

46. Schneditz D, Zierler E, Vanholder R, Eloot S. Internal filtration, filtration fraction, and blood flow resistance in high- and low-flux dialyzers. Clin Hemorheol Microcirc. 2014:58(3):455-69.

47. Schindler R, Eichert F, Lepenies J, Frei U. Blood components influence cytokine induction by bacterial substances. Blood Purif. 2001:19(4):380-7.

48. Langsdorf $\mathrm{L}$, Zydney AL. Effect of blood contact on the transport properties of hemodialysis membranes: a two-layer membrane model. Blood Purif. 1994;12(6):292-307.

49. Leypoldt JK, Cheung AK. Characterization of molecular transport in artificial kidneys. Artif Organs. 1996;20(5):381-9.

50. Vanholder R. Biocompatibility issues in hemodialysis. Clinical. Mater. 1992; 10(1-2):87-133.

\section{Submit your next manuscript to BioMed Central and we will help you at every step:}

- We accept pre-submission inquiries

- Our selector tool helps you to find the most relevant journal

- We provide round the clock customer support

- Convenient online submission

- Thorough peer review

- Inclusion in PubMed and all major indexing services

- Maximum visibility for your research

Submit your manuscript at www.biomedcentral.com/submit
Biomed Central 